\title{
Influence of sensory integration training on postural instability in elderly with parkinsonian disease following stereotactic surgery
}

\author{
Ahmed M. Elshinnawy ${ }^{\mathrm{a}}$, Amir N. Wadee $^{\mathrm{c}}$, Ahmed M. Tawfick $^{\mathrm{b}}$
}

aPhysical Therapy Department for

Neuromuscular Disorders and Surgery,

${ }^{b}$ Physical Therapy Department for Internal

Medicine and Geriatrics, Modern University for

Technology and Information, Cairo, 'Physical

Therapy Department for Basic Sciences, Cairo

University, Giza, Egypt

Correspondence to Ahmed M. Elshinnawy, PhD in Physical Therapy, Physical Therapy Department for Neuromuscular Disorders and its Surgery, Faculty of Physical Therapy, Modern University for Technology and

Information, Cairo, 12311, Egypt.

Tel: +20 1092070555

e-mail: el_shinnawy80@hotmail.com

Received 14 January 2019

Accepted 2 June 2019

Bulletin of Faculty of Physical Therapy 2019 24:90-98

\begin{abstract}
Background
Impaired posture is strongly associated with function particularly in patients with parkinsonian disease (PD).

Objective

To detect the effect of sensory integration training on postural instability in elderly PD following stereotactic surgery.

Patients and methods

A total of 27 patients with idiopathic PD were assessed before and after 12 weeks by the postural stability test. They were randomly assigned into three groups: group I (sensory integration training), group II (stereotactic surgery), and group III (sensory integration training after 10 days postoperatively).

\section{Results}

There was significant improvement in group III more than in groups I and II. The percent of improvement of group III was higher concerning the overall stability index (48.86\%, $t=7.088$ and $P=0.0001$ (, anterior/posterior index $(74.61 \%, t=21.240$ and $P=0.0001)$, and medial/lateral index $(55.81 \%, t=14.014$ and $P=0.0001)$. Group III was superior to groups I and II $(P=0.026$ and $0.001,0.040$ and 0.0001 , and 0.049 and 0.0001).

\section{Conclusion}

Sensory integration training improved postural stability in elderly with PD following stereotactic surgery.
\end{abstract}

\section{Keywords:}

parkinsonian patients, sensory integration, stereotactic surgery

Bulletin of Faculty of Physical Therapy 24:90-98

() 2019 Bulletin of Faculty of Physical Therapy

1110-6611

\section{Introduction}

Parkinsonian disease (PD) is characterized clinically by postural instability [1]. Although it is primarily a disease of the elderly, some individuals have developed PD in their 30's and 40's [2].

Postural instability, probably the most relevant symptom, leads to a poor quality of life [3]. It is particularly challenging and difficult to treat as it does not respond well to dopaminergic therapy [4]. Several studies have examined possible ways of predicting falls, with previous occurrence of falls being one of the main predictors, and several motor factors including measures assessing postural stability $[5]$.

Stereotactic surgery is a minimally invasive form of surgical intervention that makes use of a threedimensional coordinate system to locate small targets inside the body and to perform on them some action such as radiosurgery, stimulation, and ablation [6].

\section{Study design}

This was a randomized case-controlled trial with pretest-post-test experimental design. It was conducted in the outpatient clinic of Faculty of Physical Therapy, Modern University for Technology and Information, during the period from January 2018 to August 2018. Patients signed an informed consent form before their engagement. The study was approved by the Ethical Committee of Faculty of Physical Therapy, Cairo University.

\section{Sample size}

A generated sample size, using the $G^{*}$ Power software (version 3.0.10) (Germany), of at least seven participants per group would be required. Allowing for a $20 \%$ dropout rate, it was necessary to reach a total sample level of a minimum of 27 participants.

This is an open access journal, and articles are distributed under the terms of the Creative Commons Attribution-NonCommercial-ShareAlike 4.0 License, which allows others to remix, tweak, and build upon the work non-commercially, as long as appropriate credit is given and the new creations are licensed under the identical terms. 
Participants were randomly assigned using a handpicked envelope.

\section{Patients and methods}

A total of 27 patients with PD were invited to participate in the study. Their age ranged from 60 to 70 years old (16 males and 11 females). The duration of illness ranged from 5 years till 16 years. Patients were stage three according to Modified Hoehn and Yahr (HY), as well as Schwab and England scales [7], and Mini Mental State Examination score was more than 23 [8].

Participants were randomly assigned into three groups, and each group included nine patients: group I (control group) received sensory integration training, group II underwent deep brain stimulation (DBS) through stereotactic surgery, and group III received sensory integration training after 10 days postoperatively to stereotactic surgery (as illustrated in Chart 1). Postural stability was estimated by measuring the overall stability index, anterior/posterior (AP) index, and medial/lateral (M/L) index [6] before and after 12 weeks using Biodex Balance System (Biodex Medical Systems Inc., Shirley, New York, USA).

\section{Statistical analysis}

Statistical analysis was done using statistical packages for the social sciences (SPSS) version 20 for Windows (SPSS, Inc., Chicago, Illinois, USA). Paired $t$-test was used to compare within each group and one-way analysis of variance test among three groups. Posthoc multiple comparison test (least significance difference) was used to examine the superior group. Significant level of probability was $P$ value up to 0.05 .

\section{Procedure}

(1) Testing procedures:

(a) The postural stability tests: The patient's score assesses deviations from center [9]. It includes overall stability index (SI), (b) AP index, and (c) $\mathrm{M} / \mathrm{L}$ index.

(b) The Mini Mental State Examination or Folstein test [8].

(c) Timed up and go test (s) [10].

(d) The unified Parkinson's Disease Rating Scale (UPDRS) [11,12].

(e) The HY scale [7].

(2) Training procedures: Sensory integration training was done to improve both feedback and feed-

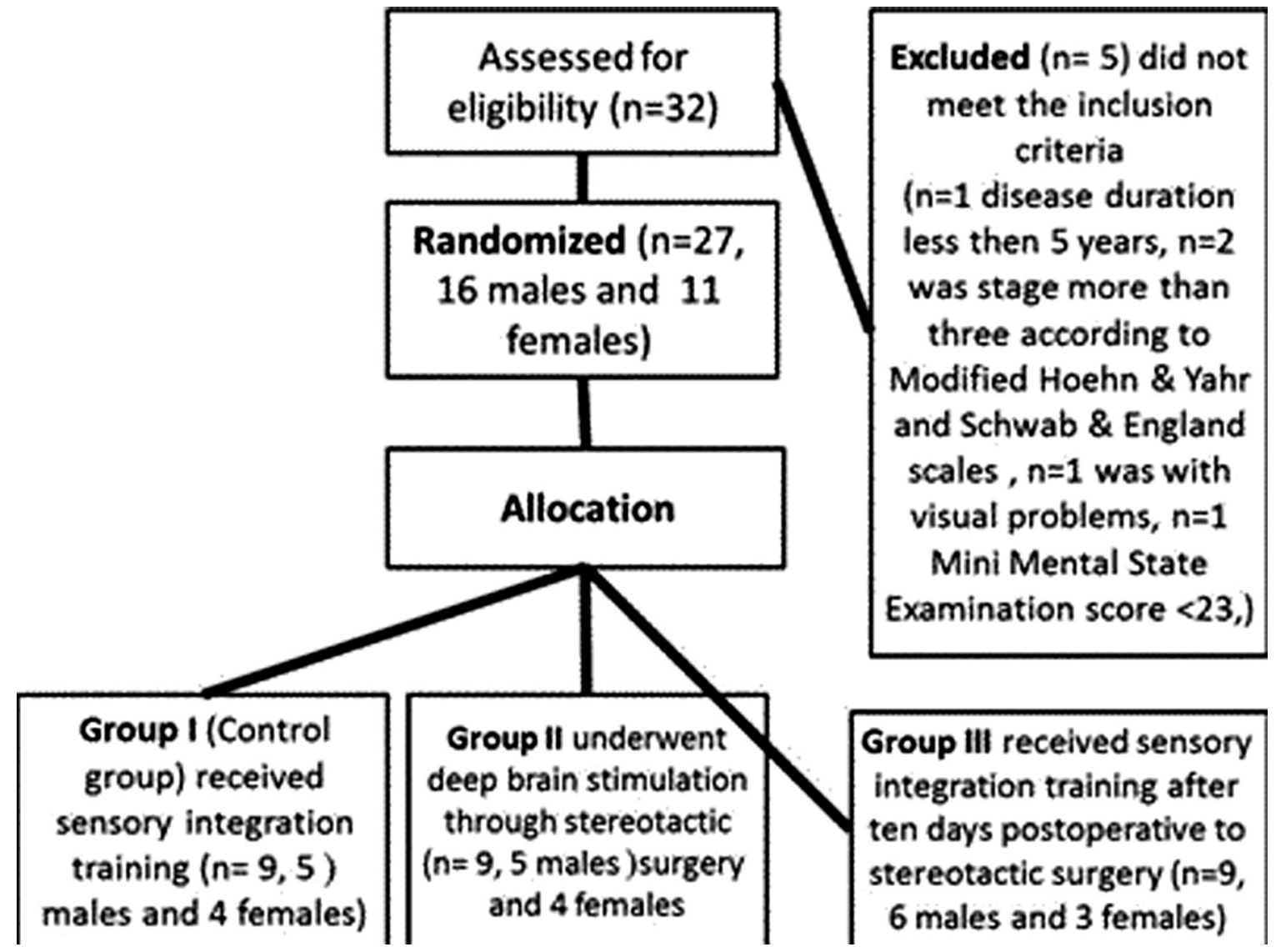


forward postural reactions. Patients were asked to repeat exercises belonging to three different predetermined groups of exercises [13,14].

\section{Results}

\section{Demographic data}

Mean values were $62.20 \pm 1.14,62.78 \pm 1.42$, and 64.22 \pm 5.09 years for ages; $71.47 \pm 5.89,69.22 \pm 3.27$, and $69.58 \pm 4.90 \mathrm{~kg}$ for body mass; $165.44 \pm 8.33,167.44$ \pm 8.53 , and $162.44 \pm 6.36 \mathrm{~cm}$ for height; $26.25 \pm 2.59$, $24.82 \pm 3.64$, and $26.51 \pm 3.37 \mathrm{~kg} / \mathrm{m}^{2}$ for BMI; 11.22 $\pm 2.53,11.60 \pm 3.26$, and $12.78 \pm 3.34$ years for duration of disease; $27.00 \pm 0.43,27 \pm 0.59$, and $27 \pm 0.55$ for mini mental scale; $7.14 \pm 0.24,7.05 \pm 0.25$, and $7.04 \pm 0.21 \mathrm{~s}$ for timed up and go test; $45.38 \pm 4.96,57 \pm 3.51$, and 45.64 \pm 4.63 for UPDRS (part III score); and $3 \pm 0.56,3 \pm 0.50$, and $3.00 \pm 0.52$ a.u. for $H Y$ staging scale values for Arbitrary unit groups I, II, and III, respectively. The sex distribution of male patients was six (66.67\%), five (55.56\%) and five (55.56\%) respectively, and for female patients was three (33.33\%), four (44.44\%), and four (44.44\%) for groups I, II, and III, respectively. The statistical analysis revealed that there were no significant differences $(P>0.05)$ among groups in values of demographic data (age, weight, height, BMI, duration of disease, mini mental scale, times up and go test, UPDRS, HY staging scale, and sex) (Table 1 and Fig. 1).

\section{Postural stability tests \\ Overall stability index}

Mean values were $1.54 \pm 0.47,1.78 \pm 0.44$ and $1.12 \pm 0.07$ preoperatively and became $2.21 \pm 0.07,2.30 \pm 0.23$ and $2.19 \pm 0.44$ postoperatively in groups I, II, and III respectively. There were significant differences within groups $(t=4.754,3.139$, and 7.088 and $P=0.001, \quad 0.014$, and 0.0001), insignificant differences among groups in pretreatment results, whereas significant differences among groups in post-treatment results $(F=0.434$ and 7.115 and $P=0.653$ and 0.004 , respectively) (Table 2 and Fig. 2).

\section{Anterior/posterior index}

Mean values were $0.60 \pm 0.11,0.77 \pm 0.13$, and $0.49 \pm 0.09$ preoperatively and became $1.69 \pm 0.42,1.79 \pm 0.58$, and $1.93 \pm 0.13$ postoperatively in groups I, II, and III, respectively. There were significant differences within groups ( $t=6.927,5.070$, and 21.240 and $P=0.0001, \quad 0.001, \quad$ and 0.0001$)$, insignificant differences among groups in pretreatment results, whereas significant differences among groups in post-treatment results $(F=0.748$ and 13.769 and $P=0.484$ and 0.0001 , respectively) (Table 3 and Fig. 3).

\section{Medial/lateral index}

Mean values were $0.45 \pm 0.14,0.43 \pm 0.05$, and $0.38 \pm 0.04$ preoperatively and became $0.74 \pm 0.16,0.56 \pm 0.07$ and $0.86 \pm 0.07$ postoperatively, in groups I, II, and III, respectively. There were significant differences within groups ( $t=2.776,2.278$ and 14.014 and $P=0.024, \quad 0.048$ and 0.0001$), \quad$ insignificant differences among groups in pretreatment results whereas there were significant differences in posttreatment results $(F=0.988$ and 15.512 and $P=0.387$ and 0.0001 respectively) (Table 4 and Fig. 4).

\section{Percentage of improvement}

The percentages of improvement were 30.32, 22.61, and $48.86 \%$ in overall stability index; 64.50, 56.98, and $74.61 \%$ in AP index; and finally 39.19, 23.21 and $55.81 \%$, in $\mathrm{M} / \mathrm{L}$ index in groups I, II, and III, respectively, which indicated a significant improvement in group III more than in groups I and II (Fig. 5).

\section{The superior group}

Post-hoc multiple comparison test (least significance difference) indicated the superiority of group III on group I and II ( $P=0.026$ and $0.001,0.040$ and 0.0001 , and 0.049 and 0.0001$)$ in overall stability index, AP stability index, and M/L. Stability index respectively. However, there was no superiority between groups I and II in all measures $(P=0.190,0.161$ and 0.183 for

Table 1 Demographic data

\begin{tabular}{lcccccc}
\hline Items & Group I & Group II & Group III & $F$ value & $P$ value & Significance \\
\hline Age (years) & $62.20 \pm 1.14$ & $62.78 \pm 1.42$ & $64.22 \pm 5.09$ & 0.409 & 0.669 & $\mathrm{NS}$ \\
Body mass $(\mathrm{kg})$ & $71.47 \pm 5.89$ & $69.22 \pm 3.27$ & $69.58 \pm 4.90$ & 0.590 & 0.562 & $\mathrm{NS}$ \\
Height $(\mathrm{cm})$ & $165.44 \pm 8.33$ & $167.44 \pm 8.53$ & $162.44 \pm 6.36$ & 0.935 & 0.406 & $\mathrm{NS}$ \\
BMI (kg/m ${ }^{2}$ ) & $26.25 \pm 2.59$ & $24.82 \pm 3.64$ & $26.51 \pm 3.37$ & 0.451 & 0.643 & $\mathrm{NS}$ \\
Duration of disease (years) & $11.22 \pm 2.53$ & $11.60 \pm 3.26$ & $12.78 \pm 3.34$ & 0.629 & 0.542 & $\mathrm{NS}$ \\
Mini mental scale & $27.00 \pm 0.43$ & $27.00 \pm 0.59$ & $27.00 \pm 0.55$ & 0.646 & 0.724 & $\mathrm{NS}$ \\
Timed up and go test (s) & $7.14 \pm 0.24$ & $7.05 \pm 0.25$ & $7.04 \pm 0.21$ & 0.546 & 0.586 & $\mathrm{NS}$ \\
Parkinson's Disease Rating Scale (part III score) & $45.38 \pm 4.96$ & $44.57 \pm 3.51$ & $45.64 \pm 4.63$ & 0.154 & 0.926 & $\mathrm{NS}$ \\
Hoehn and Yahr staging scale (a.u.) & $3.00 \pm 0.56$ & $3.00 \pm 0.50$ & $3.00 \pm 0.52$ & 0.261 & 0.772 & $\mathrm{NS}$ \\
\hline
\end{tabular}


Figure 1

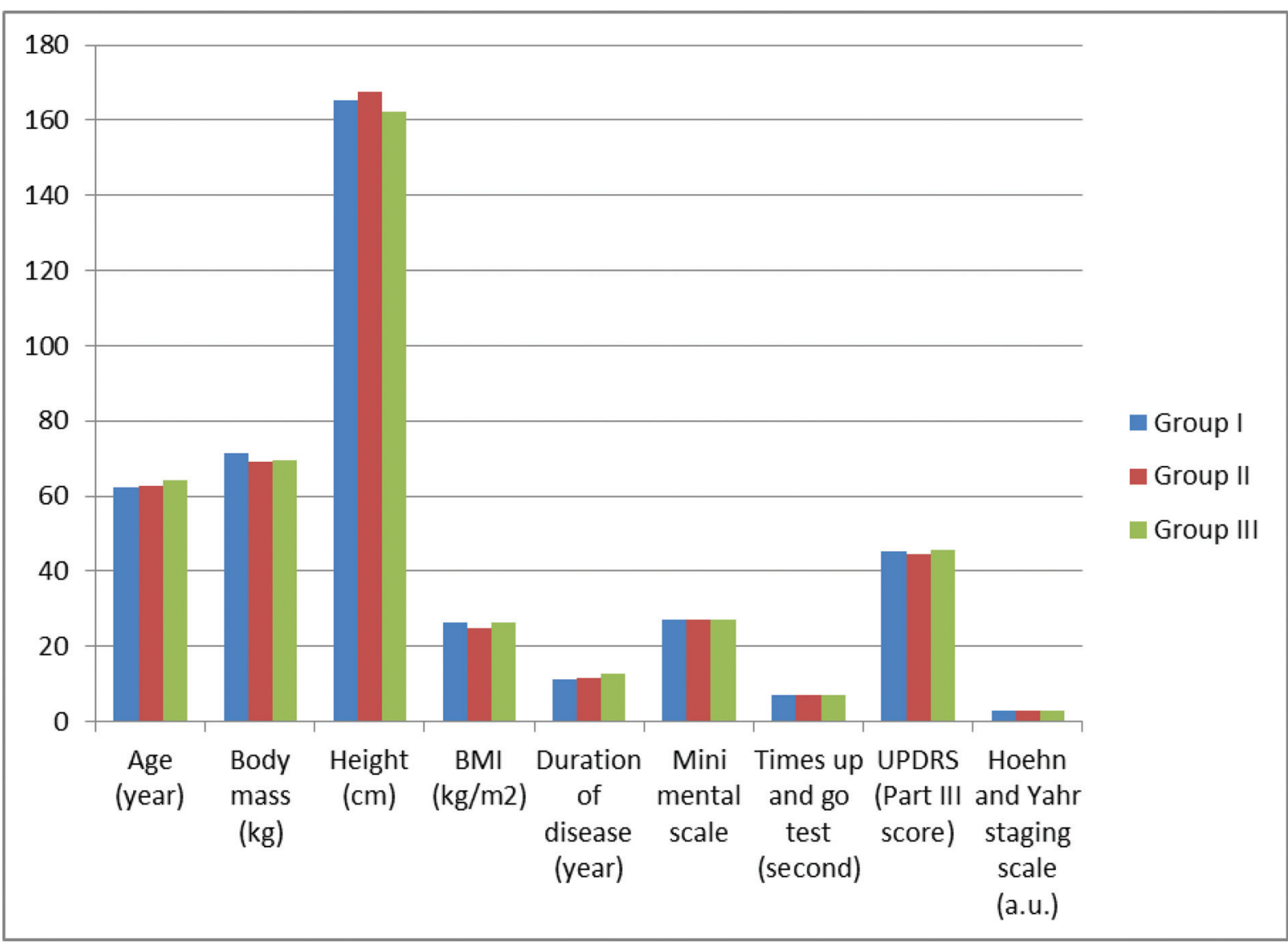

Demographic data.

Table 2 Overall stability index

\begin{tabular}{lcccccc}
\hline Items & Before treatment $($ mean \pm SD) & After treatment $($ mean \pm SD) & Improvement $(\%)$ & $t$ value & $P$ value & Significant \\
\hline Overall stability index & & & & & & \\
PT group & $1.54 \pm 0.47$ & $2.21 \pm 0.07$ & 30.32 & 4.754 & $0.001^{*}$ & $\mathrm{~S}$ \\
Surgery group & $1.78 \pm 0.44$ & $2.30 \pm 0.23$ & 22.61 & 3.139 & $0.014^{*}$ & $\mathrm{~S}$ \\
Surgery+PT group & $1.12 \pm 0.07$ & $2.19 \pm 0.44$ & 48.86 & 7.088 & $0.0001^{*}$ & $\mathrm{~S}$ \\
$F$ value & 0.434 & 7.115 & & & \\
$P$ value & 0.653 & $0.004^{*}$ & & & \\
Significant & $\mathrm{NS}$ & $\mathrm{S}$ & & & \\
\hline
\end{tabular}

PT, Group I (Control group): received sensory integration training; S, significant. *Significant.

overall stability index, AP stability index, and M/L stability index, respectively) (Table 5).

\section{Discussion}

Improving postural stability has been documented in patients with PD [15-17]. So, the mean values of overall stability index were $1.54 \pm 0.47$ in pretreatment result and became $2.21 \pm 0.07$ in posttreatment result in group I $(t=4.754$ and $P=0.001)$. Furthermore, the exercise-induced benefits on overall brain health, including increased blood flow and trophic factors and a stronger immune system, may help address the environmental need for neuroplasticity in the damaged brain [18-20]. This, in turn, results in significant improvement in the mean values of AP index from $0.60 \pm 0.11$ to $1.69 \pm 0.42$ in group I $(t=6.927$ and $P=0.0001)$.

However, effective sensory integration training protocols to improve postural stability have not yet been established. A previous study found that exercise training improved postural stability and also led to documented neurochemical and neuroplastic changes that occurred after the exercise intervention [21], so the concurrent study found a significant increase in the 
Figure 2

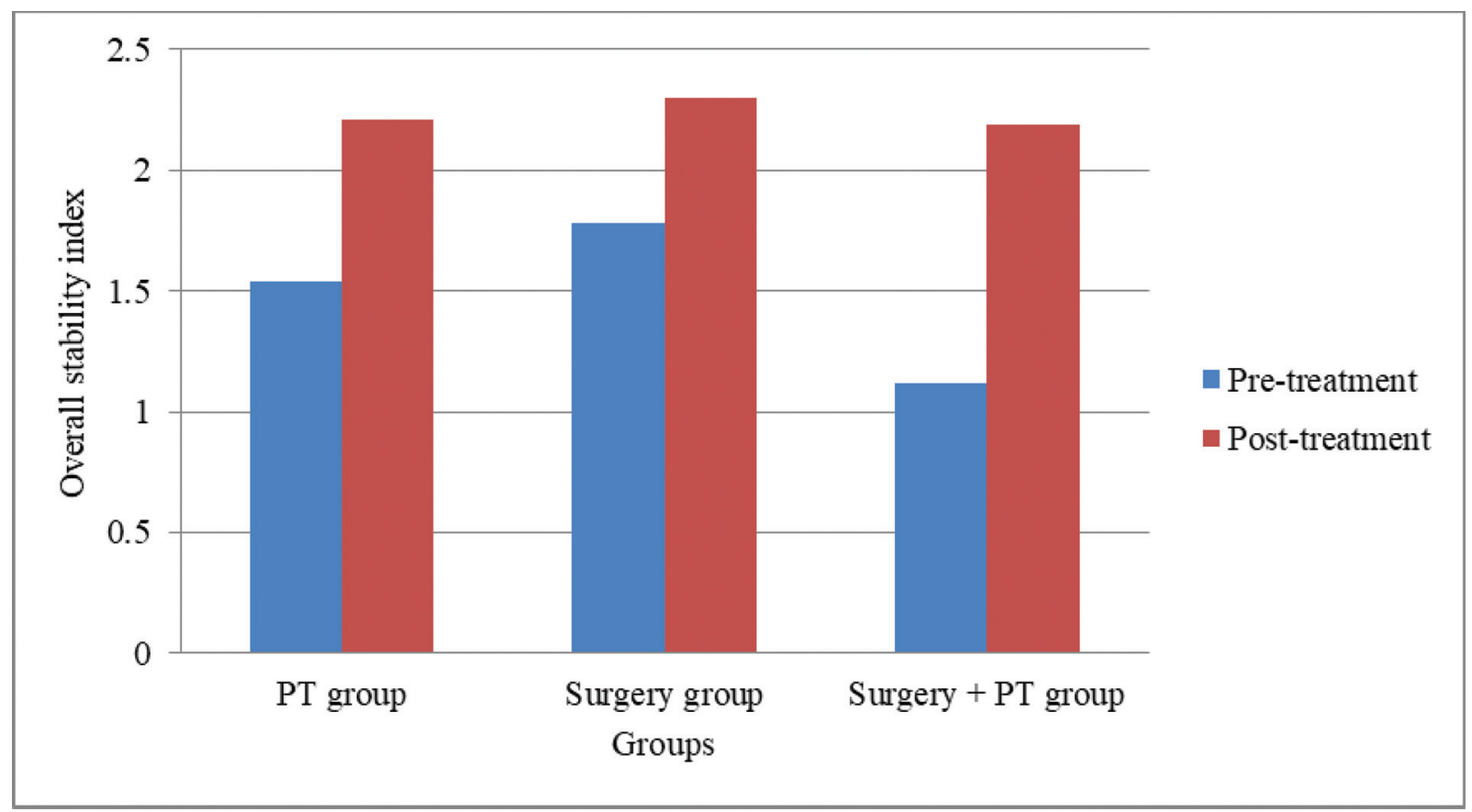

Overall stability index.

\section{Table 3 Anterior/posterior index}

\begin{tabular}{|c|c|c|c|c|c|c|}
\hline Items & Before treatment $($ mean $\pm S D)$ & After treatment $($ mean $\pm S D)$ & Improvement (\%) & $t$ value & $P$ value & Significant \\
\hline \multicolumn{7}{|l|}{ Anterior/posterior index } \\
\hline PT group & $0.60 \pm 0.11$ & $1.69 \pm 0.42$ & 64.50 & 6.927 & $0.0001^{*}$ & S \\
\hline Surgery group & $0.77 \pm 0.13$ & $1.79 \pm 0.58$ & 56.98 & 5.070 & $0.001^{*}$ & $S$ \\
\hline Surgery+PT group & $0.49 \pm 0.09$ & $1.93 \pm 0.13$ & 74.61 & 21.240 & $0.0001^{*}$ & $S$ \\
\hline$F$ value & 0.748 & 13.769 & & & & \\
\hline$P$ value & 0.484 & $0.0001^{*}$ & & & & \\
\hline Significant & NS & $\mathrm{S}$ & & & & \\
\hline
\end{tabular}

S, significant. *Significant.

Figure 3

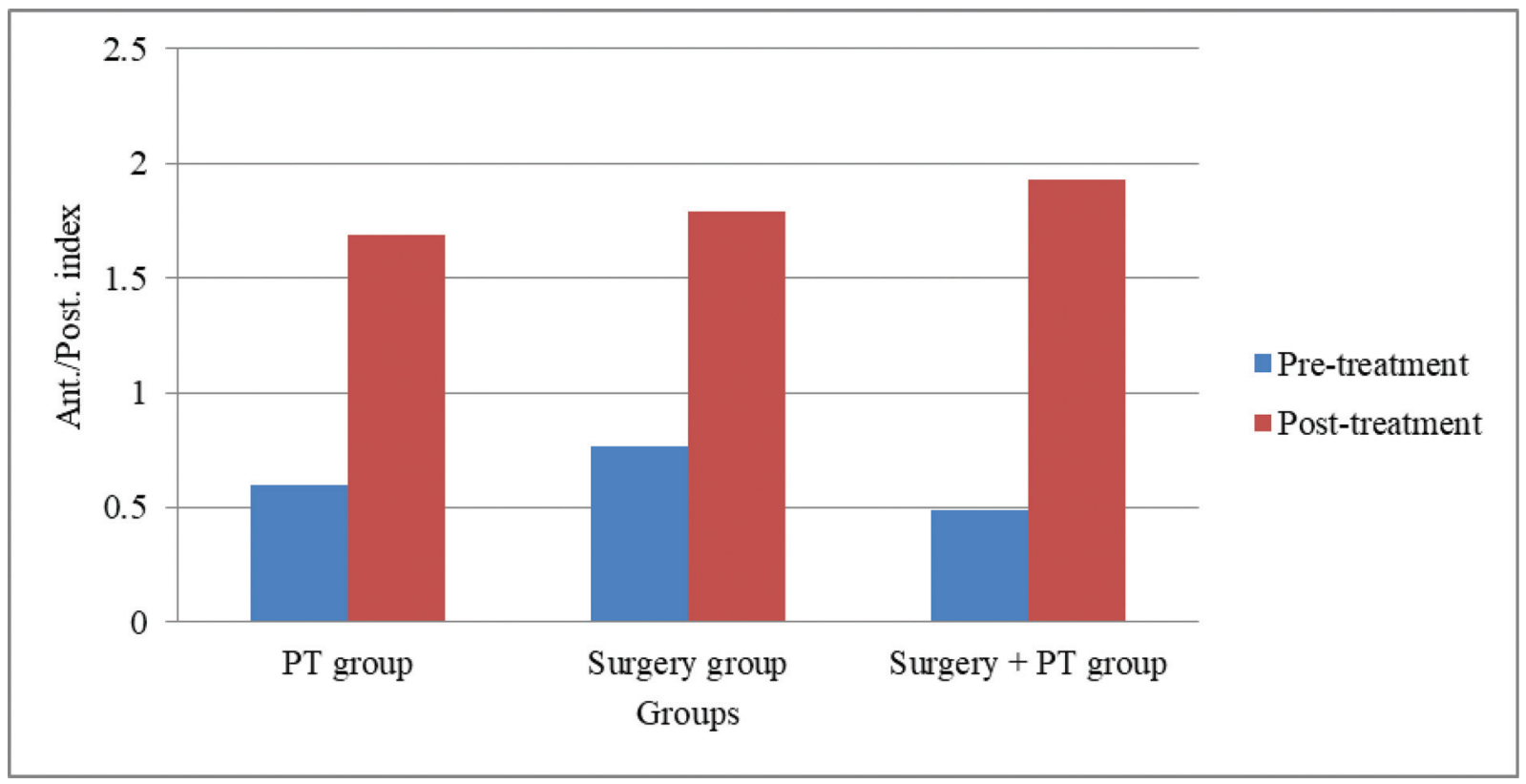


Table 4 Medial/lateral index

\begin{tabular}{lcccccc}
\hline Items & Before treatment $($ mean \pm SD) & After treatment $($ mean \pm SD) & Improvement $(\%)$ & $t$ value & $P$ value & Significant \\
\hline Medial/lateral index & & & & & & \\
PT group & $0.45 \pm 0.14$ & $0.74 \pm 0.16$ & 39.19 & 2.776 & $0.024^{*}$ & $\mathrm{~S}$ \\
Surgery group & $0.43 \pm 0.05$ & $0.56 \pm 0.07$ & 23.21 & 2.278 & $0.048^{*}$ & $\mathrm{~S}$ \\
Surgery+PT group & $0.38 \pm 0.04$ & $0.86 \pm 0.07$ & 55.81 & 14.014 & $0.0001^{*}$ & $\mathrm{~S}$ \\
$F$ value & 0.988 & 15.512 & & & \\
$P$ value & 0.387 & $0.0001^{*}$ & & & \\
Significant & $\mathrm{NS}$ & $\mathrm{S}$ & & & \\
\hline
\end{tabular}

S, significant. *Significant.

Figure 4

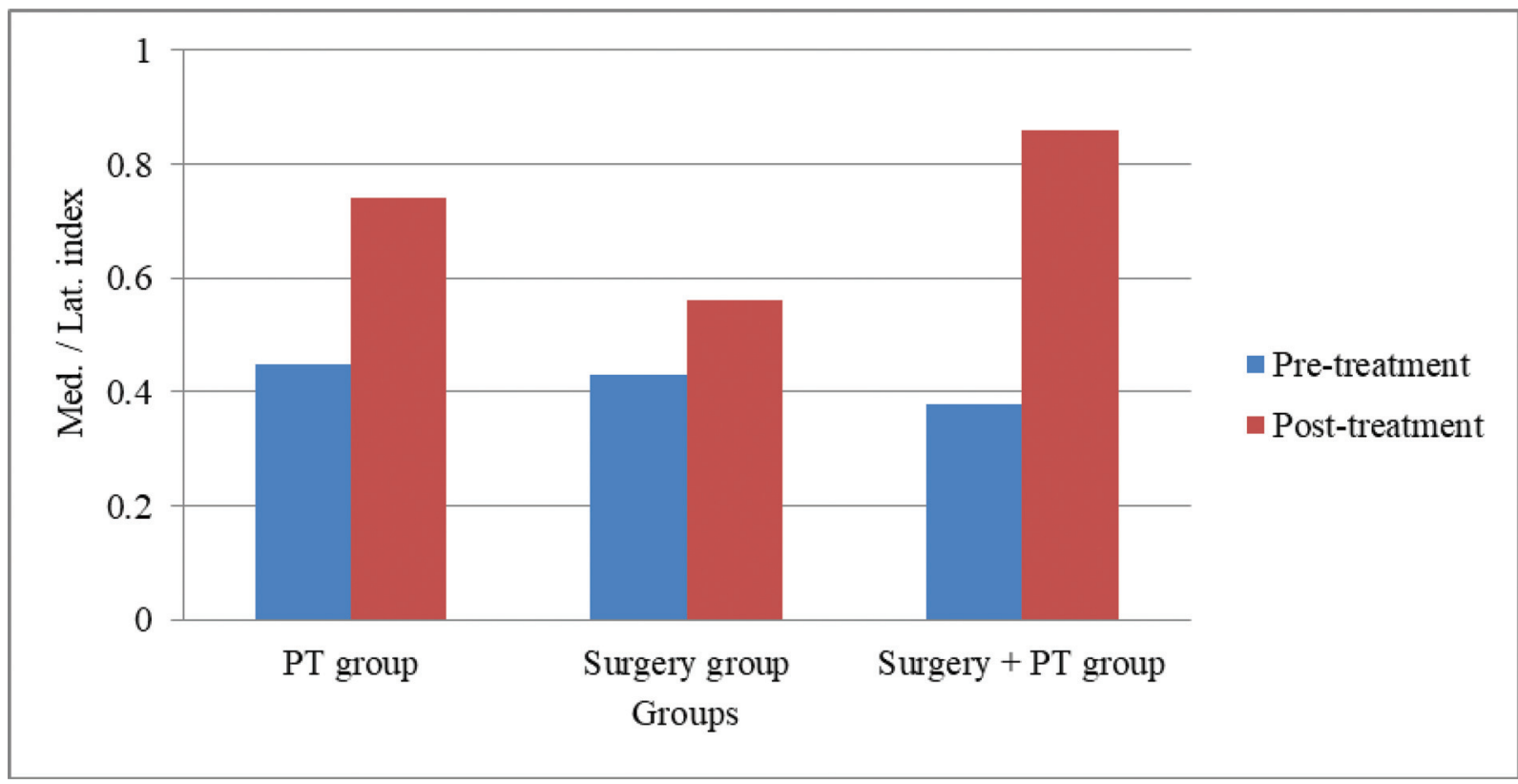

Medial/lateral index.

mean values of $\mathrm{M} / \mathrm{L}$ index from $0.45 \pm 0.14$ to 0.74 \pm 0.16 in group $\mathrm{I}(t=2.776$ and $P=0.024)$. However, this improvement was not enough to prevent falling [22] and did not exert beneficial effects on balance performance [23-27].

Furthermore, stereotactic surgery might be more effective [28-31]. Studies that used quantified gait analysis and dynamic posturography also confirmed our findings that stereotactic surgery can improve postural Instability and gait disorder [32,33]. However, its effects on PIGD are uncertain [34,35]. Based on the findings of this study, the mean values of overall stability index was $1.78 \pm 0.44$ and became 2.30 \pm 0.23 in group II $(t=3.139$ and $P=0.014)$.

The improvements in AP index values was changed from $0.77 \pm 0.13$ to $1.79 \pm 0.58$, in group II $(t=5.070$ and $P=0.001)$. However, DBS may slow functional progression because patients are more active and exercising more after surgery.
In addition, there also is evidence that exercise may improve function without preserving dopaminergic neurons presumably through compensatory mechanisms. There is growing evidence that physical activity can curb the rate of motor function decline. This was noticed in this study by the mean values of M/ $\mathrm{L}$ index, which was $0.43 \pm 0.05$ and became $0.56 \pm 0.07$ $(t=2.278$ and $P=0.048)$. Despite improvements in clinical ratings of PIGD immediately after DBS, patients tend to fall more [36].

Patients, both in group I and group II, were improved but still tend to fall, so it was the idea of adding group III, who received sensory integration training after 10 days postoperative to stereotactic surgery. Based on these findings, the mean values of overall stability index was $1.12 \pm 0.07$ and became $2.19 \pm 0.44$ ( $t=7.088$ and $P=0.0001)$. Based on the recent results, the mean values of $\mathrm{AP}$ index was $0.49 \pm 0.09$ and became $1.93 \pm 0.13(t=21.240$ and $P=0.0001)$. The mean values of $\mathrm{M} / \mathrm{L}$ index was $0.38 \pm 0.04$ and became 
Figure 5

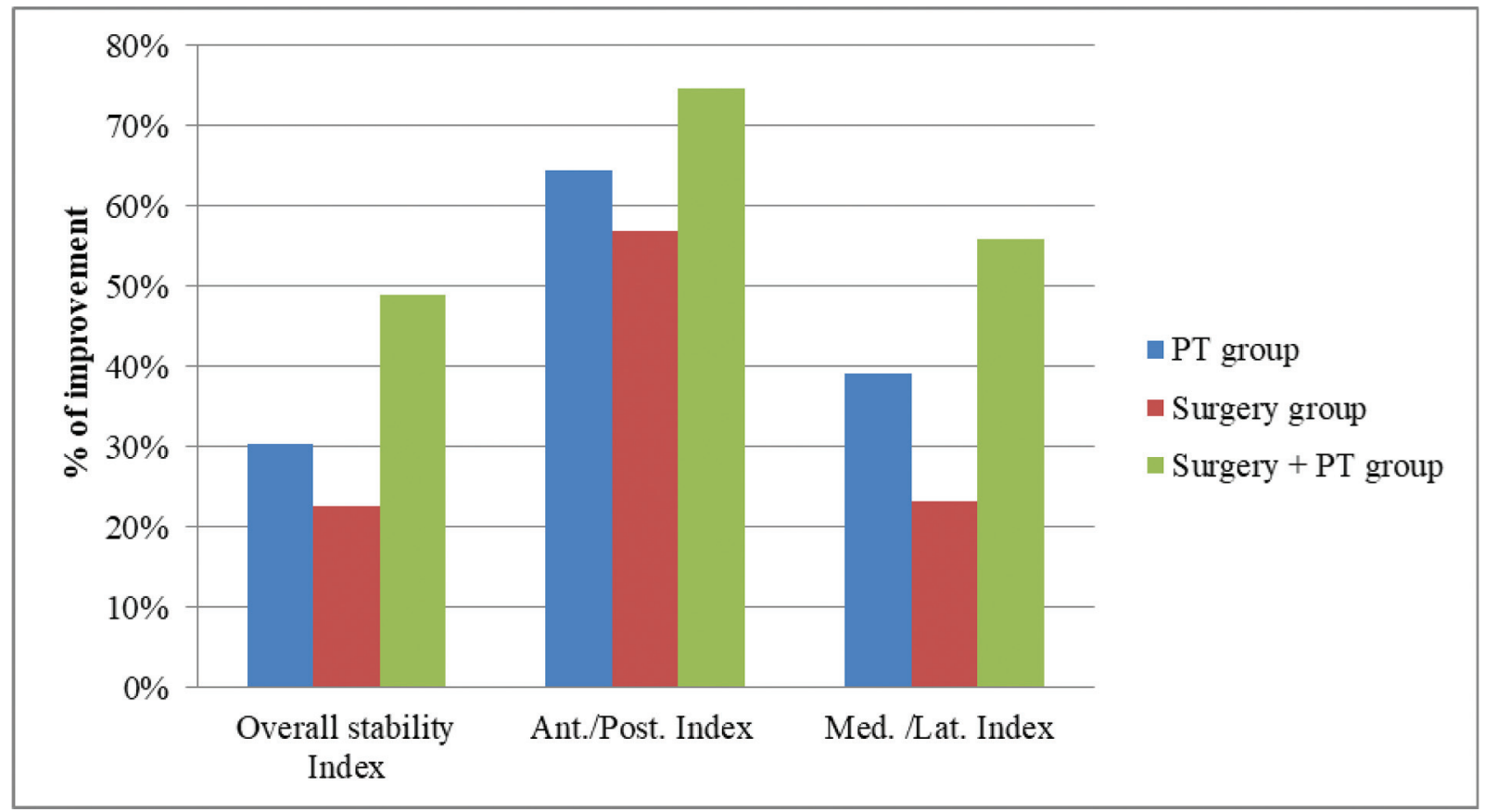

Percentage of improvement.

Table 5 Post-hoc multiple comparison test (least significance difference) for overall stability index anterior/posterior index, and medial/lateral index

\begin{tabular}{|c|c|c|c|c|}
\hline \multirow[t]{2}{*}{ Items } & \multirow[t]{2}{*}{ Means } & \multicolumn{3}{|c|}{ Groups } \\
\hline & & PT group & Surgery group & Surgery+PT group \\
\hline \multicolumn{5}{|l|}{ Overall stability index } \\
\hline PT group & $2.21 \pm 0.07$ & - & 0.190 & $0.026^{*}$ \\
\hline Surgery group & $2.30 \pm 0.23$ & & - & $0.001^{*}$ \\
\hline Surgery+PT group & $2.19 \pm 0.44$ & & & - \\
\hline \multicolumn{5}{|l|}{ Anterior/posterior index } \\
\hline PT group & $1.69 \pm 0.42$ & - & 0.161 & $0.040^{*}$ \\
\hline Surgery group & $1.79 \pm 0.58$ & & - & $0.0001^{*}$ \\
\hline Surgery+PT group & $1.93 \pm 0.13$ & & & - \\
\hline \multicolumn{5}{|l|}{ Medial/lateral index } \\
\hline PT group & $074 \pm 0.16$ & - & 0.183 & $0.049^{*}$ \\
\hline Surgery group & $0.56 \pm 0.07$ & & - & $0.0001^{*}$ \\
\hline Surgery+PT group & $0.86 \pm 0.07$ & & & - \\
\hline
\end{tabular}

${ }^{\star} P \leq 0.05$, pairs of groups significantly.

$0.86 \pm 0.07$ ( $t=14.014$ and $P=0.0001$ ). Therefore, each subsystem underlying control of posture and gait may be related to different neural circuits with varying sensitivities to levodopa or DBS [37-39]. In addition to the significant improvements within groups I, II and III, there were significant posttreatment results in- between groups $(\mathrm{F}=7.115$, 13.769, and 15.512 and $\mathrm{P}=0.004,0.0001$, and $0.0001)$. This was confirmed by the superior the percentage of improvement $(30.32,22.61$ and 48.86, 74.61, 64.50 and 56.98, 55.81, 39.19 and 23.21\%) in overall stability index, AP index and M/ $\mathrm{L}$ index in groups I, II, and III, respectively. This was confirmed by the superiority of group III on group I and II ( $P=0.026$ and $0.001,0.040$ and 0.0001 , and 0.049 and 0.0001$)$ in overall stability index, AP stability index, and $\mathrm{M} / \mathrm{L}$ stability index, respectively. Therefore, stereotactic deep brain surgery partially improved limb kinesthesia and could restore medication-induced reductions of short latency afferent inhibition, and physiotherapy can be considered as a possible treatment to correct or compensate for kinesthetic deficits [11]. Ongoing exercise and physical fitness should be highly encouraged for patients with PD who are at risk of physical deconditioning and fear of falling because it is 
beneficial with regards to physical functioning, health-related quality of life, strength, balance, and gait speed [35].

\section{Conclusion}

Accordingly, the physical therapy program should include sensory integration training for improving postural instability following stereotactic surgery in elderly with PD.

\section{Acknowledgments}

The authors are grateful to Ass. Prof. Dr. Zeiad Yosry Fayed, assistant professor of neurosurgery, Faculty of Medicine, Ain Shams University, who performed the same surgical procedures for all patients in group II. Also, the authors are appreciative to Prof. Dr. Naguib Salem, Dean Faculty of Physical Therapy, Modern University for Technology and Information, who permitted to perform all examinations and treatment procedures in laboratories and medical center of the faculty.

\section{Financial support and sponsorship \\ Nil.}

\section{Conflicts of interest}

There are no conflicts of interest.

\section{References}

1 Timothy R, James T, Robert W, Kathleen A. Parkinson's disease. Subcell Biochem 2012; 65:389-455.

2 De Lau L, Breteler M. Epidemiology of Parkinson's disease. Lancet Neurol 2006; 5:525-535.

3 Sharififar R, Coronado S, Romero H, Azari B, Thigpen M. The effects of whole body vibration on mobility and balance in Parkinson disease: a systematic review. Iran J Med Sci 2014; 39:318-326.

4 Moro E, Rodriguez O, Krack P. Long-term outcomes of surgical therapies for Parkinson's disease. Mov Disord 2012; 27:1718-1728.

5 Paul S, Sherrington C, Canning C, Fung V, Close J, Lord S. The relative contribution of physical and cognitive fall risk factors in people with Parkinson's disease: a large prospective cohort study. Neurorehabil Neural Repair 2014; 28:282-290.

6 Adrian W, Steven G, Thelekat V, Crispin J, Niall Q. Deep brain stimulation plus best medical therapy versus best medical therapy alone for advanced Parkinson's disease. Lancet Neurol 2010; 9:581-591.

7 Goetz C, Poewe W, Rascol O. Movement disorder society task force report on the Hoehn and Yar staging scale: status and recommendations. Mov Disord 2004; 19:1020-1028.

8 Pangman V, Sloan J, Guse L. An examination of psychometric properties of the mini-mental status examination and the standardized mini-mental status examination: implications for clinical practice. Appl Nurs Res 2000; 13:209-213.

9 Finn J. Biodex balance system assessment among subjects of disparate balancing abilities. Neur 2010; 75.

10 Ramaker C, Marinus J, Stiggelbout A, Margarethe H, Bob J. Systematic evaluation of rating scales for impairment and disability in Parkinson's disease. Mov Disord 2002; 17:867-876.

11 Mark G, Carpentera S, Bastiaan R, Bloemb R. Experimental neurology. Available at: http://www.elsevier.com/locate/yexnr. DOI: https://doi.org/ 10.1212/WNL.0b013e3181f61329
12 Jacob J, Crouse M, Joseph R, Phillips N, Marjan J, Ahmed A. Postural instability and falls in Parkinson's. disease. Rev Neurosci 2016; 20:1-7.

13 Song N, Canning C, Sherrington C. The effects of an exercise program on fall risk factors in people with Parkinson's disease: a randomized controlled trial. Mov Disord 2009; 25:1217-1225.

14 Adkin B, Fazakarley H, Ballinger K, Pickering T, McLellan J, Fitton S. A randomised controlled trial of a home based exercise programme to reduce the risk of falling among people with Parkinson's disease. J Neurol Neurosurg Psychiatry 2010; 78:678-684.

15 Petzinger G. Enhancing neuroplasticity in the basal ganglia: the role of exercise in Parkinson's disease. Mov Disord 2010; 25:141-145.

16 Berchtold N, Castello N, Cotman C. Exercise and time-dependent benefits to learning and memory. Neuroscience 2010; 167:588-597.

17 Petzinger G. Exercise-enhanced neuroplasticity targeting motor and cognitive circuitry in Parkinson's disease. Lancet Neurol 2013; 12:716-726.

18 Scalzo P, Kummer A, Cardoso F, Teixeira A. Serum levels of interleukin-6 are elevated in patients with Parkinson's disease and correlate with physical performance. Neurosci Lett 2010; 468:56-58.

19 Cadet $\mathrm{P}$. Cyclic exercise induces anti-inflammatory signal molecule increases in the plasma of Parkinson's patients. Int J Mol Med 2003; 12:485-492.

20 Marxreiter F, Regensburger M, Winkler J. Adult neurogenesis in Parkinson's disease. Cell Mol Life Sci 2013; 70:459-473.

21 Van der Kolk N, King L. Effects of exercise on mobility in people with Parkinson's disease. Mov Disord 2013; 28:1587-1596.

22 Kurtais $\mathrm{Y}$, Kutlay S, Tur B, Gok H, Akbostanci C. Does treadmill training improve lower-extremity tasks in Parkinson disease? A randomized controlled trial. Clin J Sport Med 2008; 18:289-291.

23 McNeely M, Earhart G. Lack of short-term effectiveness of rotating treadmill training on turning in people with mild-to-moderate parkinson's disease and healthy older adults: a randomized, controlled study. Parkinsons Dis 2012; 2012:623-630.

24 Cheng F. Factors influencing turning and its relationship with falls in individuals with Parkinson's disease. PLoS One 2014; 9:63-72.

25 Lima L, Scianni A, Rodrigues-de-Paula F. Progressive resistance exercise improves strength and physical performance in people with mild to moderate Parkinson's disease: a systematic review. J Physiother 2013; 59:7-13.

26 Liao Y. Virtual reality-based training to improve obstacle-crossing performance and dynamic balance in patients with Parkinson's disease. Neurorehabil Neural Repair 2014; 10:11-77.

27 Larissa C, Gabriela L, Tatiana S, Louise G, Elida R, Emilia M, Clecio de Oliveira G. Influence of treadmill gait training with additional load on motor function, postural instability and history of falls for individuals with Parkinson's disease: a randomized clinical trial. J Neurosci Res 2017; 21:93-100.

28 Obeso JA, Olanow CW, Rodriguez-Oroz MC, Krack P, Kumar R, Lang AE. Deep-Brain Stimulation for Parkinson's Disease Study Group. Deepbrain stimulation of the subthalamic nucleus or the pars interna of the globus pallidus in Parkinson's disease. N Engl J Med 2001; 345:956-963.

29 Chastan G, Westby J, Yelnik E, Bardinet XX, Agid M, Welter L. Effects of nigral stimulation on locomotion and postural stability in patients with Parkinson's disease. Brain 2009; 132:172-184.

30 Guehl D, Dehail P, Pdeseze M, Cuny E, Faux P, Tison F, Barat M. Evolution of postural stability after subthalamic nucleus stimulation in Parkinson's disease: a combined clinical and posturometric study. Exp Brain Res 2006; 170:206-215.

31 Patrick H, Mark S. Deep brain stimulation: a paradigm shifting approach to treat Parkinson's disease. Front Neurosc 2016; 10:173.

32 Maaike B, Rianne A, Marten M, Patricia L, Hans D, Bastiaan R. Effects of stereotactic neurosurgery on postural instability and gait in Parkinson's disease. Neurology 2004; 61:1711-1716.

33 Deborah R, Averell O, Joseph J, Sharon O, Krauss R, Grossman F Postural control in Parkinson's disease after unilateral posteroventral pallidotomy. Brain 2000; 123:2141-2149.

34 George R, Nutt J, Burchiel K, Horak F. A meta-regression of the long-term effects of deep brain stimulation on balance and gait in PD. Neurology 2010; 75:1292-1299.

35 Marsha E, Melnick P, Glenna A, Dowling D, Michael J, Aminoff M, et al Advances in therapeutic options for gait and balance in Parkinson's disease. US Neurol 2011; 7:100-108. 
36 Weaver F, Follett K, Stern M. Bilateral deep brain stimulation versus best medical therapy for patients with advanced Parkinson disease. JAMA 2009; 301:63-73.

37 Lyoo C, Aalto S, Rinne J. Different cerebral cortical areas influence the effect of subthalamic nucleus stimulation on parkinsonian motor deficits and freezing of gait. Mov Disord 2007; 22:2176-2182.
38 Rocchi L, Chiari L, Horak F. Effects of deep brain stimulation and levodopa on postural sway in Parkinson's disease. J Neurol Neurosurg Psychiatry 2002; 73:267-274

39 Shivitz N, Koop M, Fahimi J. Bilateral subthalamic nucleus deep brain stimulation improves certain aspects of postural control in Parkinson's disease, whereas medication does not. Mov Disord 2006; 21:1088-1097. 